\title{
Addiction to the Smartphone in High School Students: How It's in Daily Life?
}

\author{
Arturo García-Santillán \\ UCC Busines School, Universidad Cristóbal Colón, Mexico \\ ORCID: 0000-0001-7284-5959 \\ Ester Espinosa-Ramos \\ Sussane Wesley College, Veracruz, Mexico \\ ORCID: 0000-0001-7363-570X
}

Received: 22 Sep 2020

Accepted: 10 Nov 2020

\begin{abstract}
Nowadays, the serious situation that affects the entire world goes beyond the social, cultural, economic problems and other conflicts that occur day by day. These were left aside to move to a global alert; we refer to the pandemic crisis that all the nations of the world are facing. Confinement forced people all over the world to stay at home; therefore, communications through electronic devices became very necessary. This study does not seek to analyze the pandemic crisis; its purpose is to analyze the use that students give to their mobile phone, to determine if this has generated addiction, in addition to identifying if use differs in men and in women. Participants were 184 high school students enrolled in a public sector institution in the Port of Veracruz, Mexico. To obtain the data, the SAS-CV test was used. This contains questions related to the profile of the respondent and 10 items in Likert format. It was distributed via electronic devices for their response. The data were statistically analyzed using polychoric correlation matrices and factor analysis with component extraction. The main findings demonstrate the obtaining of three components: physiological, dependence and distraction, which account for $68 \%$ of the total variance, and it was also shown that there are no differences by gender.
\end{abstract}

Keywords: addiction smartphone, polychoric correlations matrices, principal component, factorial analysis

\section{INTRODUCTION}

Buying a mobile phone could seem harmless up to a certain point, since we have been convinced that it is a tool used by the individual to communicate with the surrounding society; however, how much has this tool become an essential need in daily life? Does constant use influence behavior? Does it cause addiction? Hence, the purpose of this study is to determine if high-school students are addicted to mobile phones and if this addiction differs in relation to gender.

\section{State of the Art}

Regarding addiction to mobile phones, the findings by Ling (2002) demonstrate that mobile phones work as a means to keep a direct and controlled communication between parents and children. Having a mobile phone has also allowed teenagers to shape an identity as part of a social group, where they have the possibility of creating a unique and exclusive language as part of said group of people. This coincides with the arguments of other similar studies (Mante \& Piris, 2002; Protegeles, 2005). 
Likewise, Ling highlights the differences by gender, since his research proved there is a larger number of women who send text messages, unlike men, who make more phone calls; these results match other studies on the subject (Bianchi \& Phillips, 2005; Madell \& Muncer, 2004).

In the chronological analysis of mobile phones made by Ling (2002), it is stated that in the year 1997 its use was oriented mainly to work matters and more men than women where in possession of a mobile phone. In 1999 there were no differences by gender because both used them; however, there was a debate about whether the use of mobile phones posed a risk if used while driving or because it emitted electromagnetic radiations, so there were people who chose not to have one. Before 2001, people of different ages owned a mobile phone, being women more prone to buy mobile phones than men; in May 2001 there was an increase in the ownership of mobile phones by men, surpassing women.

In another study carried out by Mante and Piris (2002), they point out that young Dutch people use mobile phones to send text messages as a fast way of communication since it is low-cost, convenient and indirect, thus avoiding to be face to face and exposed to confrontation. On the other hand, Madell \& Muncer (2004) demonstrated that men who do not own a mobile phone declared as their reason the fact they do not need it. Ownership is more common in young people than adults and more women than men have and use mobile phones to develop and maintain contact with others in their social relationships; several studies have obtained similar results on this issue (Carbonell et al., 2018; Geser, 2006; Hakoama \& Hakoyama, 2011; López-Fernández et al., 2017; Roberts et al., 2014).

Similarly, Kamibeppu and Sugiura (2005) carried out a study in Tokyo, where a questionnaire was applied in five public institutions to 651 middle-school students. The researchers found that the mobile phone was mainly used for e-mails, rather than phone calls. The results also showed students use mobile phones to forge friendships, though its use caused them to be awake for most part of the night, creating as well a certain insecurity about the possibility of not keeping their mobile phones at all times with them.

Srivastava (2005) mentions that in 2002, the acquisition of mobile phones surpassed that of landline phones and both e-mails and text messages became part of the preferred social communication for people who owned a mobile phone. Moreover, the inclusion of a calendar, radio, photo and video camera has increased the number of buyers who want to have everything in a single device.

Bianchi and Phillips (2005) conducted a study by surveying 195 phone users. Among their findings, they discovered age, extroversion and low self-esteem can be factors linked to the use of mobile phones. Said study ascertained that extroverts showed a higher probability of risk-taking, and that young drivers are more prone to cause automobile accidents by using their phones while driving. This matches the study by Hakoama and Hakoyama (2011).

Geser (2006) states that men perceive a mobile phone as a symbol of power and independence, not as a connection to a social environment as perceived by women. On the other hand, Sánchez-Carbonell et al. (2008) proved the use given to mobile phones can cause a maladjustment behavior, but it does not generate addiction due to the small emotional disturbance it causes. Likewise, they found there was no danger of using it as a way to hide the identity of the user, as sometimes shown by social networks or online games. Additionally, they mention mobile phones can be considered as a personal object which is dominant per se and allows socialization through phone calls, text messages, video recording or sharing and listening to music in the different contexts a person can encounter.

The elements crucial to creating addiction are the loss of control, sense of impotence and dependence on "something" which causes sensations of desire, pleasure, euphoria and relief while having it or using it. On the other hand, if one does not have it or use it, there are sensations of anxiety, irritability and hostility. Likewise, addiction is made up by those effects which harm the person both internally (thoughts, feelings, emotions) and externally (family, job, school, friends) (Sánchez-Carbonell et al., 2008).

The findings of Beranuy et al. (2009) point to mobile phones not being a cause of addiction, but there is a problem with the impulsive and abusive use of certain applications. This use is more evident in young people than in adults and, compared to men, women are more prone to excessive use in order to communicate 
emotions. In a study carried out in Sweden by Thomée et al. (2011), 4,156 young people between 20 and 24 years old were surveyed with a questionnaire and followed up for a year. At the beginning of the study they displayed a high degree of mobile phone usage: in the case of men, it was associated to symptoms of depression and sleep disorders, while in the case of women it was associated to depression symptoms. Later, at the end of the year, they were surveyed again, finding the following: in women the excessive use of mobile phones was related to stress and sleep disorders, while the stress caused by accessing applications or staying connected at all times was associated in both genders to sleep disorders and depression symptoms.

Alternatively, to identify if the use of mobile phones had an influence in children's behavioral problems, Divan et al. (2012) applied questionnaires to 28,745 children over seven years old in 2008, evidencing significant traits of behavioral disorders in those children who were exposed to mobile phones in the prenatal and postnatal stages. Afterwards, the studies by Carbonell et al. (2012) assert that the preferred way to connect to social networks or maintain communication with other young people is through the mobile phone. This leads to a being constantly aware of the phone so as not to lose contact with their social environment, whether by a phone call or text message. This comes from a fear of being left out of the group of friends they belong to and their activities. In consequence, they feel the need to respond as soon as they receive a call or message.

In contrast, Lepp et al. (2015) carried out a study where a questionnaire was applied to a random sample of 454 students. Said research proved extroverted young people who use the mobile phone just a little experienced less boredom, had a tendency towards challenges and were oriented to the detection of opportunities and benefits compared to other groups. They also found those who used their mobile phones more showed higher leisure angst, unlike other surveyed groups.

According to Roberts et al. (2014), the use of mobile phones can be a way to evade problems such as: low self-esteem, guilt, insecurity, boredom, stress, anxiety or couple issues, to mention a few, by compensating or forgetting their current feelings. In a study by Tosell et al. (2015), it is mentioned that the applications of e-mail, text messages, Facebook and internet drove the use of mobile phones in addicted users, while the use of games was the same among both addicted and non-addicted users. It was also determined that the mobile phone is not the source of addiction as such. Rather, it is the content which can be accessed through it what drives excessive use, as shown by other research on the matter (Beranuy et al., 2009; SánchezCarbonell et al., 2008).

The high use of mobile phones by young people has been predominant among female users, as a way to keep interpersonal relations, as highlighted by De-Sola et al. (2016), who also declared its use is linked to personality traits like neurosis, extroversion, impulsiveness, self-esteem, self-image and identity. Additionally, it was associated to stress, anxiety, sleep disorders and to a lesser extent, depression, as well as the use of alcohol and cigarettes. Likewise, Sung (2016) proved in a study that single adults showed more addiction to mobile phones than those who were married and mobile phones are used as a way to reduce some tension regarding the environment where they are. The study concludes with the suggestion to advise those adults who present traits of mobile phone addiction in order to create awareness of the matter and avoid excess.

Other studies such as those by Gutiérrez-Rentería, Santana-Villegas, and Pérez-Ayala (2017) evaluated the use that Hispanic young people between 18 and 25 years of age make of their smartphone. The results yielded evidence that indicates the use they give to their smartphone, with applications that satisfy the need for communication among young people, since they use WhatsApp at least five hours a day, which makes it the social network of greater importance to communicate between friends and family. They also showed a direct relationship between hours of use, choice of the brand, the choice to use the smartphone for social networks, all with respect to gender.

The current rapid changes in the digital environment have brought about new communication processes in contemporary society. This is particularly true in adolescents, who are increasingly involved in new technologies to communicate with each other. All this, thanks to the appearance of different mobile communication applications, which have served as communication channels between youth to name a 
population. On this idea, Leiva, Benavides, and Wilkinson, (2017) carried out a study in which they sought to measure the emotions of young Hispanics in Chile, Mexico and the United States. The main findings show similarities and differences with regard to motivations and smartphone use among Hispanics. Their findings highlight the differences in terms of the time they spend on social networks, the personal and commercial value they give to information, as well as preferences towards mobile devices. In addition, the analysis allowed them to identify three archetypes which they called "always connected", "entertained" and "safe". This last archetype refers to users who need their phones to feel personal safety.

In other recent studies on mobile phone addiction, it is possible to find the one by Carbonell et al. (2018), who applied a survey to 792 college students, finding an increase in the use of social networks as a result of mobile phone use, as well as music applications. They highlight the importance of taking into account the studies done in the period of 2006-2016, since there is a difference between mobile phones from said time and current ones. The first mobile phones did not allow internet access, and now smartphones have an endless number of applications which allow indiscriminate access at any time. Thus, it is important to consider the cultural influence and context of the research on technology and instruments used, in order to update them if necessary to know the perception on their use.

In South Korea, Cha and Seo (2018) did not find a relationship between the demographic characteristics of Koreans and mobile phone addiction. Furthermore, they found that mobile phones are used to access social networks and play online as a way to relieve stress and keep in touch with others. People addicted to mobile phones reduce face to face contact, leading $\mathrm{Cha}$ and Seo to point out the relation between excessive use and shyness and loneliness experienced by an individual, who will increase its use the more he or she experiences these feelings.

About the subject of mobile phone addiction, Oviedo-Trespalacios et al. (2019) conducted a research in Australia, discovering anxiety as one of the traits related to mobile phone use, which is also linked to unsafe behaviors, such as driving a vehicle while using mobile phones, something that can lead to severe accidents. Another finding was that women between the ages of 18 and 25 years old used mobile phones more frequently.

Finally, it is important to point out that the mobile phone is playing a very important role in every human activity; it constitutes a tool and a means to carry out these activities. An example of this is information consumption. Young people report that their phones are the most important source of news (Albarello, 2020).

At this point, the theoretical arguments have been previously described and, in order to answer the research questions and contrast the work hypotheses, the method followed for the empirical study is described next.

\section{DESIGN AND METHOD}

Considering that the object of study is focused on determining the factor structure underlining mobile phone addiction, the method responds to the hypothetical-deductive quantitative paradigm. This research has a non-experimental design since the independent variables $(\mathrm{X})$ are not manipulated to modify their effect $(\mathrm{Y})$. From the hypothetic-deductive paradigm, the present study tries to contrast the hypothesis suggesting highschool students have mobile phone addiction and the existence of a difference by gender (Behar, 2008). Additionally, this study is transversal as the application of the instrument took place at a single time. The type of study is descriptive, correlational, of difference of means, and explanatory.

Firstly, the characteristics associated to the demographic profile of the surveyed population are described, in order to develop the statistical analysis of the sample data next. With the factor structure obtained, we will have the bases to explain the component matrix variance given by the results and with the one-factor ANOVA analysis, it will be possible to infer if there is a difference by genders.

Participants. The participants were high-school students of a public academic institution in the Port of Veracruz, Mexico. The sample was non-probabilistic because it was only authorized to survey all enrolled 
students who agreed to participate. The total were 184 students who were invited to participate and whose main requirement was to be enrolled in one of the study terms (semesters) and up to date in their school obligations. Besides, they were informed that anonymity would be guaranteed at all times by the confidentially criteria of the participants.

Instrument. The SAS-SV (Smartphone addiction scale- short version) scale designed by Kwon, Kim, Cho \& Yang (2013) was used. The SAS-SV scale is a validated scale originally built in South Korea, but published in English (Kwon et al., 2013b). It is made up of 10 items which are classified on a Likert-type dimensional scale whose response range is: 1 means rarely, 2 occasionally, 3 frequently, 4 often and 5 always. The total score is between 10 and 60, the highest score being the indicator of the presence of "smartphone addiction" in the last year. The original SAS-SV showed very acceptable internal consistency Cronbach's alpha: 0.91 (LopezFernandez, 2015). For its application, this scale was designed electronically (Google forms) and given to all the classroom teachers so that whenever they considered appropriate, students could answer the survey, whether in their mobile phones, laptops or other devices from which they could access the platform where the survey was located. The estimated response time was approximately from 7 to 10 minutes.

Procedure. In order to answer the research questions and prove the hypotheses, the technique of exploratory factor analysis (EFA) was used. To validate the data matrix Cronbach's alpha index was used for internal consistency. Afterwards, the correlations calculation was done to identify if the data matrix is an identity matrix or not, which could prevent the use of this technique.

Other measures which allow justifying the pertinence of the factorial technique are Bartlett's test of sphericity with KMO, $\mathrm{Chi}^{2}$ test with $n$ degrees of freedom and significance $<0.01$, the measure of sample adequacy (MSA) and factorial loadings. The decision criteria are: reject $\mathrm{HO}$ if calculated $\mathrm{Chi}^{2}$ is bigger than $\mathrm{Chi}^{2}$ from tables and do not reject if not.

EFA explains the set of observed variables by an underlying structure of variables called factors (Kline, 20002005), with the aim that the covariance of every indicator in the scale of every dimension of the proposed variable can be empirically identified (Yela, 1966). On this matter, literature suggests that the type of correlation to be applied depends on the measurement level (Ogasawara, 2011).

It is recommended to use a Pearson correlation for continuous variables, a Tetrachoric (TCC) matrix for dichotomic variables and a Polychoric (PCC) correlation matrix if the variables are composed, dichotomic or ordinal, if all of them are ordinal or if there is a combination of ordinal and continuous.

Furthermore, in the specific case of instruments designed with Likert scales, such as the mobile phone use scale, the use of polychoric and tetrachoric matrix (depending on the case) is necessary for the factor analysis (Ogasawaras, 2011; Richaud, 2005). Lastly, the variance analysis (ANOVA) is carried out to contrast if there are significant differences among variables in relation to gender.

\section{Data Analysis}

The results of the data analysis were: Cronbach's alpha index, which measures the reliability and internal consistency of the instrument, was 0.781 , an acceptable number according to theoretical criteria (Hair, Anderson, \& Tatham, 1979).

The sample was composed of 85 men $(51.8 \%)$ and 79 women $(48.2 \%)$ whose ages were: 14 years old (16 cases $-9.8 \%$ ), 15 years old ( 52 cases - 31.7\%), 16 years old ( 26 cases - $15-.9 \%$ ), 17 years old ( 54 cases - $32.8 \%$ ) and 18 years old (16 cases - 9.8\%). Next, the data base is analyzed to observe the behavior of the mobile phone addiction phenomenon. For this, the descriptive terms presented in Table $\mathbf{1}$ are analyzed first, later the differences of means by gender are measured and finally, the data matrix is assessed, using the polychoric correlations and factorization.

The value of the mean shows that the frequencies of smartphone use or affectation to determined actions is in the range of "occasionally" and "frequently" considered by the scale of mobile phone addiction, where 1) means rarely, 2) occasionally, 3) frequently, 4) often and 5) always. 
Table 1. Descriptive statistics

\begin{tabular}{lcccccccccc}
\hline Statistics & $\mathrm{X} 1$ & $\mathrm{X} 2$ & $\mathrm{X} 3$ & $\mathrm{X} 4$ & $\mathrm{X} 5$ & $\mathrm{X6}$ & $\mathrm{X} 7$ & $\mathrm{X} 8$ & $\mathrm{X} 9$ & $\mathrm{X} 10$ \\
\hline $\mathrm{N} \quad$ Valid & 164 & 164 & 164 & 164 & 164 & 164 & 164 & 164 & 164 & 164 \\
$\quad$ Lost & 0 & 0 & 0 & 0 & 0 & 0 & 0 & 0 & 0 & 0 \\
Mean & 1.93 & 1.79 & 2.13 & 1.79 & 1.72 & 2.22 & 3.09 & 2.92 & 2.63 & 2.05 \\
Typ. Dev. & 1.083 & 1.127 & 1.285 & 1.078 & 1.006 & 1.209 & 1.351 & 1.392 & 1.234 & 1.277 \\
Variance & 1.173 & 1.270 & 1.651 & 1.163 & 1.013 & 1.461 & 1.826 & 1.938 & 1.523 & 1.630 \\
Kurtosis & -.038 & .779 & -.256 & 1.785 & 1.997 & -.327 & -1.099 & -1.177 & -.921 & -.280 \\
Typ. Kurtosis error & .377 & .377 & .377 & .377 & .377 & .377 & .377 & .377 & .377 & .377 \\
Minimum & 1 & 1 & 1 & 1 & 1 & 1 & 1 & 1 & 1 & 1 \\
Maximum & 5 & 5 & 5 & 5 & 5 & 5 & 5 & 5 & 5 & 5 \\
\hline
\end{tabular}

Source: own

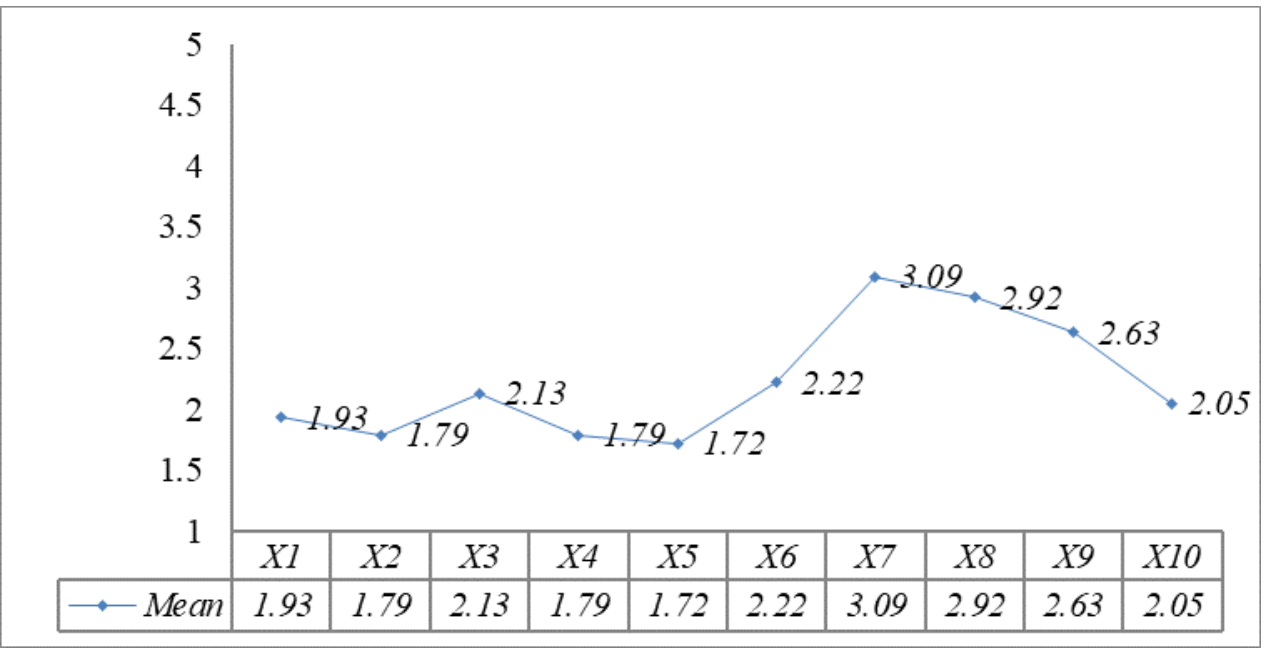

Figure 1. Mean values in the indicators (Source: own)

The indicators $\mathrm{X} 7, \mathrm{X} 8$ y $\mathrm{X} 9$ are apparently more concentrated in the frequency level 3 according to the Likert scale: in the first place, this means that participants of the study frequently refer to how smartphones have an influence in their daily lives, since they regularly check notificiations of social networks and they dedicate more time than they should to the use of their smartphone. The mean of the rest of the indicators is in the range of rarely and occasionally.

To strengthen the test, it is analyzed if there is a difference of means by gender and then the ANOVA test is calculated with statistic $F$ and its significance, which are presented in Table $\mathbf{2}$.

It is possible to see in Table 2 the values of the statistic $F$ with its level of significance, which considers how if the intra-groups significance level (sig.) is lower or equal to 0.05 ; then the hypothesis of equality of means should be rejected. On the contrary, if the value is higher, then, the equality of means is accepted, meaning there are no significant differences among the groups. In the case of indicators $X 1$ and $X 10$, the values are less than 0.05 , so it can be assumed that there is a difference of means by gender in these indicators, which is not the case for the remaining eight indicators ( $X 2$ al $X 9)$.

Table 3 presents the Levene statistic to prove the hypothesis of equality of means and the hypothesis of equality of population variances.

With the purpose of contrasting the hypothesis of equality of population variances, the statistic of Levene is calculated. The criteria establish that if the critical level (sig.) is $\leq$ than 0.05 , the hypothesis of equality of variances is rejected. Conversely, if it is $>$ the hypothesis of equality of variances is accepted. The value obtained for $X 1$ and $X 4(\leq 0.05)$ suggests the rejection of the hypothesis of equality of variances, which does not happen in $X 2, X 3, X 5$ to $X 10$ where there is seemingly an equality of variances. 
Table 2. Anova

\begin{tabular}{|c|c|c|c|c|c|c|}
\hline & & Sum of squares & $\mathrm{df}$ & Quadratic mean & $\mathrm{F}$ & Sig. \\
\hline \multirow[t]{3}{*}{$\mathrm{X} 1$} & Inter-groups & 6.877 & 1 & 6.877 & 6.047 & .015 \\
\hline & Intra-groups & 184.245 & 184 & 1.137 & & \\
\hline & Total & 191.122 & 185 & & & \\
\hline \multirow[t]{3}{*}{$\mathrm{X} 2$} & Inter-groups & 3.742 & 1 & 3.742 & 2.983 & .086 \\
\hline & Intra-groups & 203.209 & 184 & 1.254 & & \\
\hline & Total & 206.951 & 185 & & & \\
\hline \multirow[t]{3}{*}{$\mathrm{X} 3$} & Inter-groups & 4.387 & 1 & 4.387 & 2.685 & .103 \\
\hline & Intra-groups & 264.662 & 184 & 1.634 & & \\
\hline & Total & 269.049 & 185 & & & \\
\hline \multirow[t]{3}{*}{$X 4$} & Inter-groups & 4.039 & 1 & 4.039 & 3.527 & .062 \\
\hline & Intra-groups & 185.492 & 184 & 1.145 & & \\
\hline & Total & 189.530 & 185 & & & \\
\hline \multirow[t]{3}{*}{$\mathrm{X} 5$} & Inter-groups & .001 & 1 & .001 & .001 & .980 \\
\hline & Intra-groups & 165.097 & 184 & 1.019 & & \\
\hline & Total & 165.098 & 185 & & & \\
\hline \multirow[t]{3}{*}{$\mathrm{X} 6$} & Inter-groups & 1.432 & 1 & 1.432 & .981 & .324 \\
\hline & Intra-groups & 236.665 & 184 & 1.461 & & \\
\hline & Total & 238.098 & 185 & & & \\
\hline \multirow[t]{3}{*}{$x 7$} & Inter-groups & 3.985 & 1 & 3.985 & 2.199 & .140 \\
\hline & Intra-groups & 293.643 & 184 & 1.813 & & \\
\hline & Total & 297.628 & 185 & & & \\
\hline \multirow[t]{3}{*}{$x 8$} & Inter-groups & 3.098 & 1 & 3.098 & 1.604 & .207 \\
\hline & Intra-groups & 312.872 & 184 & 1.931 & & \\
\hline & Total & 315.970 & 185 & & & \\
\hline \multirow[t]{3}{*}{ X9 } & Inter-groups & 3.746 & 1 & 3.746 & 2.481 & .117 \\
\hline & Intra-groups & 244.565 & 184 & 1.510 & & \\
\hline & Total & 248.311 & 185 & & & \\
\hline \multirow[t]{3}{*}{$\mathrm{X} 10$} & Inter-groups & 8.042 & 1 & 8.042 & 5.058 & .026 \\
\hline & Intra-groups & 257.568 & 184 & 1.590 & & \\
\hline & Total & 265.610 & 185 & & & \\
\hline
\end{tabular}

Source: own

Table 3. Proof of homogeneity of variance

\begin{tabular}{lcccc}
\hline & Levene statistic & df1 & df2 & Sig. \\
\hline X1 & 8.569 & 1 & 184 & .004 \\
X2 & 2.114 & 1 & 184 & .148 \\
X3 & 1.749 & 1 & 184 & .188 \\
X4 & 3.951 & 1 & 184 & .049 \\
X5 & .225 & 1 & 184 & .636 \\
X6 & .862 & 1 & 184 & .355 \\
X7 & .106 & 1 & 184 & .745 \\
X8 & .237 & 1 & 184 & .627 \\
X9 & 3.666 & 1 & 184 & .057 \\
X10 & 2.023 & 1 & 184 & .157 \\
\hline
\end{tabular}

Source: own

The matrix of polychoric correlation among variables is shown in Table 4 (the 10 items).

As observed in Table 4 with the polychoric correlation matrix, the values of the 10 items in the scale show acceptable correlations, proving it is not an identity matrix, meaning there would be no correlation among variables. Furthermore, it is necessary to justify the pertinence of the factorial technique; hence we calculate Bartlett' test of sphericity with Kaizer, which should be in a range between ( 0 and 1$)$, the value of $\mathrm{Chi}^{2}$, the values of sample sufficiency and variance and significance $<0.05$. All of these are presented in Table 5 . 
Table 4. Polychoric correlation matrix

\begin{tabular}{|c|c|c|c|c|c|c|c|c|c|c|}
\hline Variables & $\mathrm{X} 1$ & $\mathrm{X} 2$ & X3 & $X 4$ & $\times 5$ & $\mathrm{X} 6$ & $\times 7$ & $\mathrm{X} 8$ & $\times 9$ & $\mathrm{X} 10$ \\
\hline X1 & 1.000 & & & & & & & & & \\
\hline$x 2$ & 0.229 & 1.000 & & & & & & & & \\
\hline X3 & 0.314 & 0.103 & 1.000 & & & & & & & \\
\hline$X 4$ & 0.323 & 0.235 & 0.631 & 1.000 & & & & & & \\
\hline$\times 5$ & 0.338 & 0.205 & 0.508 & 0.567 & 1.000 & & & & & \\
\hline$x 6$ & 0.306 & 0.159 & 0.713 & 0.566 & 0.460 & 1.000 & & & & \\
\hline$x 7$ & 0.266 & 0.230 & 0.431 & 0.392 & 0.360 & 0.470 & 1.000 & & & \\
\hline$x 8$ & 0.249 & 0.273 & 0.488 & 0.356 & 0.343 & 0.517 & 0.879 & 1.000 & & \\
\hline X9 & 0.386 & 0.220 & 0.530 & 0.410 & 0.469 & 0.510 & 0.541 & 0.550 & 1.000 & \\
\hline X10 & 0.272 & 0.210 & 0.470 & 0.483 & 0.424 & 0.347 & 0.504 & 0.465 & 0.514 & 1.000 \\
\hline
\end{tabular}

Source: own

Table 5. Bartlett' test of sphericity, $\mathrm{Chi}^{2}$ and (KMO) index. Polychoric correlation matrix adequacy

\begin{tabular}{lcc}
\hline Kaiser-Meyer-Olkin Measure (KMO) & & 0.83756 \\
\hline BC Boottstrap 95\% confidence interval (0.826 a 0.887) & Approx. Chi-square & 819.00 \\
\hline Bartlett' test of sphericity & $d f$ & 45 \\
& Sig. & 0.000010 \\
\hline
\end{tabular}

Source: own

Table 6. Sampling adequacy and variance explained

\begin{tabular}{lccc}
\hline Variable & Eigenvalue & Proportion of variance & Cumulative proportion of variance \\
\hline X1 & 4.78704 & 0.47870 & 0.47870 \\
X2 & 1.10536 & 0.11054 & 0.58924 \\
X3 & 0.99399 & 0.09940 & 0.68864 \\
X4 & 0.74631 & 0.07463 & \\
X5 & 0.68178 & 0.06818 & \\
X6 & 0.50850 & 0.05085 & \\
X7 & 0.48834 & 0.04883 & \\
X8 & 0.32105 & 0.03210 & \\
X9 & 0.26062 & 0.02606 & \\
X10 & 0.10701 & 0.01070 & \\
\hline
\end{tabular}

Source: own

The value obtained from the contrast of Bartlett' test of sphericity, Chi ${ }^{2}$ with $45 d f=819.00 ;(p<0.00001)$ shows we can reject the null hypothesis assuming the variables under analysis are not correlated, which is why in this case we can consider the correlations matrix to be adequate for factorization. Additionally, the measure of sample adequacy Kaiser-Meyer-Olkin ( $\mathrm{KMO}=0.83756)$ also reveals that the correlation matrix is adequate for analysis. With the results of Bartlett' test of sphericity and KMO (>0.80) which is significant $(p<0.05)$, it is possible to do the factorial analysis. With this consideration, we have the possibility of analyzing the factorial structure of the instrument used in this study; therefore, the sample adequacy and explained variance is calculated from the parallel analysis. Table 6 presents the value obtained from the sample adequacy and explained variance.

In Table 6 the eigenvalues representing the explaining power of the extracted variance are presented. It can be seen that there are three factors extracted under the eigenvalues criteria $>1$ and thus, 68.86\% of the assimilable variance is explained by these three factors. With the purpose of extracting the indicators with higher scores, a Varimax orthogonal rotation is carried out. This procedure is selected to achieve a better result; the application of an orthogonal rotation facilitates the interpretation of the components and helps to assimilate each of the variables in an axis. The number of uncorrelated variables can be reduced in this manner. Table 7 presents the rotated component matrix. 
Table 7. Rotated component matrix (a)

\begin{tabular}{|c|c|c|c|}
\hline \multirow[t]{2}{*}{ Variable } & \multicolumn{3}{|c|}{ Component } \\
\hline & 1 & 2 & 3 \\
\hline X3 & .794 & & \\
\hline$X 4$ & .755 & & \\
\hline$x 6$ & .710 & & \\
\hline X5 & .664 & & \\
\hline $\mathrm{X} 8$ & & .917 & \\
\hline $\mathrm{X7}$ & & .905 & \\
\hline X9 & & .531 & \\
\hline \multicolumn{4}{|l|}{ X10 } \\
\hline $\mathrm{X} 2$ & & & .817 \\
\hline $\mathrm{X} 1$ & & & .558 \\
\hline
\end{tabular}

Extraction method: Principal component analysis. Rotation method: Varimax with Kaiser Normalization. ${ }^{\text {a }}$ The rotation has converged in 5 iterations

Table 7 displays the three extracted components, which are integrated by the indicators with the highest scores (>0.5). The composition of the components is the following:

For component 1: The users frequently feel pain in the wrists, back and neck due to the use of smartphones $(X 1.3,0.794)$, they cannot stand to be without their phones $(X 1.4,0.755)$ and often have their phones in their mind when they are not using them $(X 1.6,0.710)$. This causes the users to feel impatient and irritable when they do not have their smartphone at the moment $(X 1.5,0.664)$; apparently, these indicators can be related to physical and mental characteristics and so, they could be interpreted as a physiological component.

For component 2: Regarding the second component, the surveyed users display a high frequency use of reviewing social network notifications in their mobile phones $(X 1.8,0.917)$, producing in them the feeling that their life is highly influenced by the use of their smartphones $(X 1.7,0.905)$ and they are even using their smartphones for more time than they should, causing in the user a feeling of concern $(X 1.9,0.531)$. This factor or component can be defined as a dependency component.

For component 3: Finally, there is a third component made up by indicators regarding the difficulty of concentrating, whether it is in class, doing homework or even at work, because of the use of their smartphones $(X 1.2,0.817)$. Furthermore, the use of smartphones has caused a distraction for the student when doing a properly planned work $(X 1.1,0.558)$. This factor or component can be defined as a distraction component.

\section{DISCUSSION AND CONCLUSION}

The aim of the study was focused on determining if high-school students presented mobile phone addiction and if this addiction differs in relation to gender, the results on this regard were: in the first place, the instrument of mobile addiction designed by Kwon et al. (2013) that was used in this research showed an acceptable internal consistency $(\alpha=0.781)$, while the polychoric correlation matrix showed an acceptable correlation between the studied variables, which were in the range of 0.103 to 0.879 and all of them were positive, proving it is not an identity matrix and it does not present multicollinearity problems.

Afterwards, the exploratory factor analysis allowed obtaining three components, which were orthogonally rotated with Varimax and given the following denominations: physiological component, dependency component and distraction component, together they explained $68 \%$ of the variance. Despite the fact that the instrument designed by Kwon et al. (2013) is visualized as unidimensional and its aim is to evaluate mobile phone or smartphone addiction, there too have been studies where the existence of more than one factor was reported, as it was the case in this study.

By examining the indicators of the physiological component, it can be seen that this factor contributes to $46.87 \%$ of the variance. In addition, the physiological name derives from the indicators related to the pain 
felt in the back, wrists and neck because of the use of smartphones, as well as the feeling of not being able to resist being without the phone or having it constantly in mind, generating a feeling of impatience and irritability in users.

Regarding the dependency component, which explains $11.05 \%$ of the total variance, the indicators were found to be related to a high frequency use of mobile phones, since users are constantly reviewing their social networks. This sense of dependency is related to knowing what people are thinking about him/her, making people aware of what they are doing, where are they going on holidays or even if they are just in a restaurant or doing any sort of activity, constantly posting on their social networks and thus, people are constantly checking their social networks to see who is watching them or giving them a like. The former leads to an excessive use or at least more use than advisable of mobile phones, which apparently is already a concern for the user.

Finally, there is a third component which explains $9.94 \%$ of the variance, referred to as distraction component because its indicators are related to the loss of concentration caused by the use of mobile phones when doing a task or activity, either inside or outside the class, or just about anywhere. This excessive use is already affecting users negatively when doing a proper planning of a task or activity. Consequently, when engaging in an activity without a defined plan, no matter how basic, there is greater chance of mistakes. This distraction is caused by the excessive use of smartphones.

These traits which were found in each component and were the reason for the given name were seemingly identified in other research. For instance, Hooper and Zhou (2007) associated the use of smartphones to six behavior categories: habitual, dependent, compulsive, addictive, mandatory and voluntary so these authors suggest mobile phone use can be classified in these categories.

Nonetheless, excessive use of mobile phones should not necessarily be seen as a negative addiction, as stated by Cassidy (2006), who points out that the person who spends a lot of time using this mobile technology could significantly reduce his/her chances of developing other harmful habits, such as alcohol and tobacco consumption.

With regards to this study's aim of determining if there were differences in mobile phone addiction in relation to gender, results showed no significant evidence of this. Even though it is true that in the ANOVA test (Table 2), the values of $X 1$ and $X 10$ indicators were less than 0.05 , leading us to assume the existence of difference by gender means, the other eight indicators ( $X 2$ to $X 9$ ) did not show the existence of any differences. At the same time, the hypothesis of equal variances in the population with the Levene statistic (Table 3 ) was contrasted and it was possible to see that the values obtained for $X 1$ and $X 4$ are $\leq 0.05$, suggesting the hypothesis of equal variances must be rejected; however, the rest of indicators $(X 2, X 3, X 5$ to $X 10)$ showed evidence of equal variances.

In both cases, the indicator $X 10$ showed a similar behavior regarding the existence of differences by gender, but in the factorization, specifically in the calculation of the rotated matrix for the extraction of components, this indicator did not have a significant loading according to the Varimax rotation and for this reason it was excluded from the components matrix (Table 7).

Not finding differences by gender, these results seem to match other studies like the ones by Billieux et al. (2008) and Cuesta (2019). Although results in this research suggest there are no differences by gender in the studied population, there have been significant differences in gender in other studies, for example, Beranuy et al. (2009) proved the abuse of smartphones to bring about more negative consequences in women; similarly, Takao et al. (2009) identified a higher probability of excess use of smartphones in women compared to men. In the same manner, Chóliz, Villanueva, and Chóliz (2009) found Spanish women between 12 and 18 years old displayed a higher use of the mobile phone than men.

After this analysis and as a constructive self-critic, it is recommended to widen the sample of other surveyed populations in Latin American contexts; moreover, this sample was non-probabilistic and auto-selected, firstly because of the easiness to apply the questionnaire and secondly, for the economic constraints to collect data, so it would be worth to select stratified samples for comparative studies. 
It would be important to study other possible implications on the physical damage caused by the addiction to mobile phones as well. One such study was carried out by Heinrich, Thomas, Heumann, von Kries, and Radon, (2011), who have pointed out that there have been studies to research the neurological and neuropsychological effects which could harm the cranial base, even cause intracranial tumors, all this because mobile phones work with the emission and reception of low-frequency electromagnetic waves.

Other possibilities would be to carry out studies in the Mexican context where phone harassment could be measured, replicating the studies by Turan, Polat, Karapirli, Uysal, and Turan, (2011) or research the negative effect of sensorial interference caused by the excessive use of mobile phones while driving an automobile, as studied by Backer-Grøndahl and Sagberg (2011).

It would also be convenient to develop studies such as those of Albarello (2020) to be able to identify the use that Mexican students give the smartphone, in a kind of comparison with Argentine students, to verify if their behavior is similar, as users of news spaces. In addition, it is suggested to explore in parallel studies, not only the addiction that could prevail in students towards the internet and the mobile phone, but specifically to social networks, as was the study by Leiva, Benavides, and Wilkinson, (2017), since in the findings they reported, they identified excessive use of WhatsApp.

\section{REFERENCES}

Albarello, F. (2020). De la hegemonía al nicho: desplazamiento de medios tradicionales en rutinas informativas de un grupo de universitarios argentinos [From hegemony to the niche: displacement of traditional media in informative routines of a group of Argentine university students]. Dixit, 32, 46-60. https://doi.org/10.22235/d.vi32.1946

Backer-Grøndahl, A., \& Sagberg, F. (2011). Driving and telephoning: Relative accident risk when using handheld and hands-free mobile phones. Safety Science, 49, 324-330. https://doi.org/10.1016/j.ssci.2010.09.009

Behar, D. (2008). Metodología de la investigación [Investigation methodology]. Cuba: Shalom.

Beranuy, M., Chamarro, A., Graner, C., \& Carbonell, X. (2009). Validación de dos escalas breves para evaluar la adicción a Internet y el abuso de móvil [Validation of two short scales to assess Internet addiction and mobile abuse]. Psicothema, 21, 480-485.

Bianchi, A., \& Phillips, J. (2005). Psychological predictors of problem mobile phone use. Cyberpsychology \& Behavior, 8(1), 39-51. https://doi.org/10.1089/cpb.2005.8.39

Billieux, J., Van der Linden, M., \& Rochat, L. (2008). The role of impulsivity in actual and problematic use of the mobile phone. Applied Cognitive Psychology, 22, 1195-1210. https://doi.org/10.1002/acp.1429

Carbonell, X., Chamarro, A., Oberst, U., Rodrigo, B., \& Prades, M. (2018). Problematic use of the internet and smartphones in university students: 2006-2017. Int. J. Environ. Res. Public. Health, 15(475), 1-13, doi:10.3390/ijerph15030475.

Carbonell, X., Fúster, H., Chamarro, A., \& Oberst, U. (2012). Adicción a internet y móvil: una revisión de estudios empíricos españoles [Internet and mobile addiction: a review of Spanish empirical studies]. Papeles del Psicólogo-Roles of the Psychologist, 33(2), 82-89.

Cassidy, S. (2006). Using social identity to explore the link between a decline in adolescent smoking and an increase in mobile phone use. Health Education, 106, 238-250. https://doi.org/10.1108/09654280610658578

Cha, S., \& Seo, B. (2018). Smartphone use and smartphone addiction in middle school students in Korea: Prevalence, social networking service, and game use. Health Psychology Open, 1-15. https://doi.org/10.1177/2055102918755046 
Chóliz, M., Villanueva, V., \& Chóliz, M. C. (2009). Ellas, ellos y su móvil: Uso, abuso (¿y dependencia?) del teléfono móvil en la adolescencia [They, them and their mobile: Use, abuse (and dependence?) Of mobile phones in adolescence]. Revista Española de Drogodependencias-Spanish Journal of Drug Addiction, 34, 74-88.

Cuesta, V. (2019). Bases psicológicas de la adicción al "Smartphone" [Psychological bases of the addiction to "Smartphone"] (Doctoral Thesis). Universidad Complutense de Madrid (Complutense University of Madrid), Madrid, Spain. Retrieved from https://eprints.ucm.es/54208/1/T40984.pdf

De-Sola, J., Rodríguez, F., \& Rubio, G. (2016). Cell-Phone Addiction: A Review. Frontiers in Psychiatry, 175(7), 1-15. https://doi.org/10.3389/fpsyt.2016.00175

Divan, H., Khelfets, L., Obel, C., \& Olsen, J. (2012). Cell phone use and behavioural problems in young children. Journal of Epidemiology \& Community Health, 66(6), 524-539. https://doi.org/10.1136/jech.2010.115402

Geser, H. (2006). Are girls (even) more addicted? Some gender patterns of cell phone usage. Sociology in Switzerland: Sociology of the Mobile Phone. Retrieved from http://socio.ch/mobile/t_geser3.pdf

Gutiérrez-Rentería, M. E., Santana-Villegas, J. C., \& Pérez-Ayala, M. (2017). Smartphone: usos y gratificaciones de los jóvenes en México en 2015. [Smartphone: Uses and gratifications for Mexican youth in 2015]. Palabra Clave, 20(1), 47-68. https://doi.org/10.5294/pacla.2017.20.1.3

Hair, J., Anderson, R., \& Tatham, R. (1979). Multivariate Data Analysis: With Readings. Tulsa, Oklahoma: PPC Books. Published by Prentice Hall PTR. ISBN 10: 0023490209 ISBN 13: 9780023490200.

Hakoama, M., \& Hakoyama, S. (2011). The impact of cell phone use on social networking and development among college students. The American Association of Behavioral and Social Sciences Journal, 15(4), 120.

Heinrich, S., Thomas, S., Heumann, C., von Kries, R., \& Radon, K. (2011). The impact of exposure to radio frequency electromagnetic fields on chronic well-being in young people. A cross-sectional study based on personal dosimetry. Environment International, 37, 26-30. https://doi.org/10.1016/j.envint.2010.06.008

Hooper, V., \& Zhou, Y. (2007). Addictive, dependent, compulsive? A study of mobile phone usage. 20th Bled eConference eMergence: Merging and Emerging Technologies, Processes, and Institutions. Junio 4-6; Bled: Slovenia. Retrieved from http://ecom.fov.uni-mb.si/proceedings.nsf/0/637808f705bd12 d2c12572ee007a38f8/\$FILE/22_Hooper.pdf

Kamibeppu, K., \& Sugiura, H. (2005). Impact of the mobile phone on junior high-school students' friends hips in the Tokyo metropolitan area. Cyberpsychology \& Behavior, 8(2), 121-130. https://doi.org/10.1089/cpb.2005.8.121

Kline, P. (2000). Handbook of Psychological Testing ( $2^{\mathrm{a}}$ ed.). New York: Routledge.

Kline, R. (2005). Structural equation modeling. New York: Guilford Press.

Kwon, M., Kim, D.-J., Cho, H., \& Yang, S. (2013). The Smartphone Addiction Scale: Development and validation of a short version for adolescents. PLos ONE, 8(12), e83558. https://doi.org/10.1371/journal.pone.0083558

Leiva Soto, R., Benavides Almarza, C., \& Wilkinson, K. T. (2017). Young Hispanics' motivations to use smartphones: A three-country comparative study. Comunicación y Sociedad, 30(4), 13-26. https://doi.org/10.15581/003.30.3.13-26 
Lepp, A., Li, J., Barkley, J., \& Salehi-Esfahani, S. (2015). Exploring the relationships between college student's cell phone use, personality and leisure. Comput. Hum. Behav., 43, 210-219. https://doi.org/10.1016/j.chb.2014.11.006

Ling, R. (2002). Chicas adolescentes y jóvenes adultos varones: dos subculturas del teléfono móvil. Estudios de Juventud, 57(2), 33-46.

Lopez-Fernandez, O. (2017). Short version of the smartphone addiction scale adapted to Spanish and French: Towards a cross-cultural research in problematic mobile phone use. Addictive Behaviors, 64, 275-280. https://doi.org/10.1016/j.addbeh.2015.11.013

López-Fernández, O., Kuss, D., Romo, L., Morvan, Y., Kern, L., ... Billieux, J. (2017). Self-reported dependence on mobile phones in young adults: A European cross-cultural empirical survey. Journal of Behavioral Addictions, 6(2), 168-177. https://doi.org/10.1556/2006.6.2017.020

Madell, D., \& Muncer, S. (2004). Back from the beach but hanging on the telephone? English adolescent's attitudes and experiences of mobile phones and the Internet. Cyberpsychology \& Behavior, 7(3), 359367. https://doi.org/10.1089/1094931041291321

Mante, E., \& Piris, D. (2002). El uso de la mensajería móvil por los jóvenes en Holanda. Estudios de Juventud, 57(2), 47-58.

Ogasawara, H. (2011). Asymptotic expansions of the distributions of the polyserial correlations coefficients. Behaviormetrika, 38(2), 153-168. https://doi.org/10.2333/bhmk.38.153

Oviedo-Trespalacios, O., Nandavar, S., Newton, J., Demant, D., \& Phillips, J. (2019). Problematic use of mobile phones in Australia... Is it getting worse? Frontiers in Psychiatry, 10(105), 1-18. https://doi.org/10.3389/fpsyt.2019.00105

Protegeles (2005). Seguridad infantil y costumbres de los menores en el empleo de la telefonía móvil. Protegeles y Defensor del Menor. Retrieved from https://bit.ly/3idd4Py

Richaud, M. (2005). Desarrollos del análisis factorial para el estudio de ítems dicotómicos y ordinales. Revista Interdisciplinaria, 22(2), 237-251.

Roberts, J., Yaya, L., \& Manolis, C. (2014). The invisible addiction: Cell-phone activities and addiction among male and female college students. Journal of Behavioral Addictions, 3(4), 254-265. https://doi.org/10.1556/JBA.3.2014.015

Sánchez-Carbonell, X., Beranuy, M., Castellana, M., Chamarro, A., \& Oberst, U. (2008). La adicción a Internet y al móvil, ¿̇moda o trastorno? Adicciones, 20(2), 149-160. https://doi.org/10.20882/adicciones. 279

Srivastava, L. (2005). Mobile phones and the evolution of social behaviour. Behaviour \& Information Technology, 24, 111-129. https://doi.org/10.1080/01449290512331321910

Sung, W. (2016). A study on the internet addiction in the smart era. Advanced Science and Technology Letters, 127, 102-107. https://doi.org/10.14257/astl.2016.127.21

Takao, M., Takahashi, S., \& Kitamura, M. (2009). Addictive personality and problematic mobile phone use. CyberPsychology \& Behavior, 12, 501-507. https://doi.org/10.1089/cpb.2009.0022

Thomée, S., Härenstam, A., \& Hagberg, M. (2011). Mobile phone use and stress, sleep disturbances, and symptoms of depression among young adults: A prospective cohort study. BMC Public Health, 11, 66. https://doi.org/10.1186/1471-2458-11-66

Tosell, C., Kortum, P., Shepard, C., Rahmati, A., \& Zhong, L. (2015). Exploring smartphone addiction: insights from long-term telemetric behavioral measures. Int J Interact Mob Technol, 9, 37-43. https://doi.org/10.3991/ijim.v9i2.4300 
Turan, N., Polat, O., Karapirli, M., Uysal, C., \& Turan, S. G. (2011). The new violence type of the era: Cyber bullying among university students: Violence among university students. Neurology, Psychiatry and Brain Research, 17, 21-26. https://doi.org/10.1016/j.npbr.2011.02.005

Yela, M. (1966). Los tests y el análisis factorial [Tests and factor analysis]. In B. Szekeli (Ed.), Los Tests (p. 153178). Buenos Aires: Kapelusz.

Young, K. S. (1996). Caught in the Net: how to recognize the signs of Internet addiction and a winning strategy for recovery. New York: John Wiley \& Sons.

Young, K. S. (1996). Internet addiction: The emergence of a new clinical disorder. Paper presented at the 104th annual meeting of the American Psychological Association, August 11, 1996. Toronto, Canada.

Young, K. S. (1998). Internet Addiction: The Emergence of a new clinical disorder. Cyber psychol Behav., 1, 237-244. https://doi.org/10.1089/cpb.1998.1.237

\section{ANNEX 1}

\section{Indicators of the SAS Short Version}

X1 Missing planned work due to smartphone use.

X2 Having a hard time concentrating in class, while doing assignments, or while working due to smartphone use.

X3 Feeling pain in the wrists or at the back of the neck while using a smartphone

X4 Won't be able to stand not having a smartphone.

X5 Feeling impatient and fretful when I am not holding my smartphone.

X6 Having my smartphone in my mind even when I am not using it.

X7 I will never give up using my smartphone even when my daily life is already greatly affected by it.

X8 Constantly checking my smartphone so as not to miss conversations between other people on Twitter or Facebook.

X9 Using my smartphone longer than I had intended

X10 The people around me tell me that I use my smartphone too much.

Correspondence: Arturo García-Santillán, UCC Busines School, Universidad Cristóbal Colón, Mexico. E-mail: agarcias@ucc.mx 